\title{
Assessment of door handles as potential reservoirs of drug-resistant enterococci
}

\author{
Kome Otokunefor ${ }^{*}$ (i), Blessing O. Famakin and Dorothy O. Douglas
}

\begin{abstract}
Background: Fomites have long been known to play a key role in the spread of disease causing agents. Hospitalassociated fomites in particular have been linked with transmission of members of the Enterococci sp which are key human pathogens. Few studies have explored the role non-hospital door handles might play as potential sources of these isolates. This study therefore set out to explore this role.

Results: A total of hundred toilet and office door handles in a tertiary institution in Rivers State, Nigeria, were sampled using the swab and rinse method. The presence and drug susceptibility of Enterococcus was determined using the selective bile esculin agar (BEA) and standard microbiological methods. Growth on BEA was observed in $71 \%$ of cases, with more growth (38/50,76\%) observed from toilet door handles. Only $35 \%$ of samples produced the characteristic black pigmentation associated with Enterococcus sp. Six different bacterial groups were identified from this subset with Enterococcus sp. making up only 14\% (5/35) of the isolates. All (100\%) Enterococci were isolated from toilet door handles. Antibiotic susceptibility testing revealed very high levels of resistance (80-100\%) against $75 \%$ of the test antibiotics. An analysis of the antibiotic resistance pattern of each isolate revealed 11 unique antibiogram patterns. Only 2 of these patterns were associated with the enterococci, with majority (4/5) exhibiting resistance to Augmentin (AUG), Ceftazidime (CAZ), Ceftriaxone (CTR), Cefuroxime (CRX), Cloxacillin (CXC), Erythromycin (ERY), Gentamicin (GEN), Ofloxacin (OFL) (antibiogram of AUG-CAZ-CRX-CTR-CXC-ERY). None of the enterococci, however, was resistant to vancomycin.

Conclusion: This study reports low level contamination of door handles by enterococci. Identical antibiogram patterns linked with majority of the enterococci could however point at the occurrence of a single clone perhaps indicating single source contamination. Reports of high levels of ampicillin resistance among these isolates are problematic as ampicillin-gentamicin combination is the treatment of choice for nosocomial enterococci pathogens.
\end{abstract}

Keywords: Drug resistance, Enterococci, Vancomycin, Fomites, Nigeria

\section{Background}

Though initially known for being commensals, presently, enterococci are notorious as key human pathogens. These organisms are predominantly associated with nosocomial infections and have been described as the third most commonly occurring nosocomial pathogen (Murray 1990; Selleck et al. 2019). A key problem associated with the enterococci is the issue of drug resistance.

\footnotetext{
*Correspondence: kome.otokunefor@uniport.edu.ng

Department of Microbiology, Faculty of Science, University of Port Harcourt, PMB 5323, Port Harcourt, Nigeria
}

Nosocomial strains of this organism are known for the rapid acquisition of drug resistance determinants and subsequent spread within an already susceptible population. The enterococci are a hardy species, able to survive harsh environmental conditions and exhibiting resistance to things such as desiccation, disinfection (García-Solache and Rice 2019). A critical step in the journey of the enterococci to act as pathogens is the colonisation of the patient (Selleck et al. 2019).

This colonisation has been thought to occur either prior to hospitalisation or following hospitalisation. A number of studies have focused on exploring the presence 
of these organisms in hospital environments in a bid to understand transmission and initiate control measures (Michael et al. 2017). Though some clones of enterococci appear adapted to hospital environments, a number of clones particularly of Enterococcus faecalis have been associated with both hospitals and other reservoirs (Guzman Prieto et al. 2016). Studies have therefore explored colonisation of enterococci, particularly vancomycinresistant enterococci (VRE) in healthy individuals in a bid to fine tune control measures and explore effectiveness. Gurnee and colleagues reported lower carriage rates in healthy children as opposed to children with prior exposure to health care settings (Gurnee et al. 2014). One risk for VRE carriage has been found to be exposure to health care settings (Davis et al. 2020). Transmission occurs between colonised patients, healthcare workers and none colonised patients often via fomites and hand colonisation (Rosenthal et al. 2014; Ferng et al. 2015; Kim et al. 2018). Few studies have however explored the role nonhospital surfaces might play as potential sources of these isolates. This study therefore set out to explore the role various non-hospital door handles play as potential reservoirs of drug-resistant enterococci.

\section{Methods}

\section{Sample collection and processing}

A total of 100 samples were aseptically collected from toilet and office door handles in a tertiary institution in Rivers State, using the swab and rinse method (Reynolds et al. 2005), using sterile swab sticks. Following sample collection and transport to the Medical Microbiology laboratory of the University of Port Harcourt, samples were immediately processed by inoculation to bile esculin agar.

\section{Purification and identification}

Colonies showing features characteristic of Enterococcus (black pigmentation), were then subcultured to nutrient agar, purified and characterised using an array of biochemical tests including: Gram stain, catalase, Voges Proskauer, starch hydrolysis, motility, fermentation of glucose, sucrose, lactose and mannitol and growth at $60{ }^{\circ} \mathrm{C}$ and $6.5 \%$ sodium chloride (Cowan and Steel 1985; Cheesbrough 2006).

\section{Antibiotic susceptibility testing}

Susceptibility testing was carried out on isolates using the disc diffusion method as previously described (Bauer et al. 1966). In brief an inoculum corresponding to 0.5 McFarland standard was inoculated to a Mueller Hinton agar plate using a sterile swab stick. After a $15 \mathrm{~min}$ preincubation period, commercially prepared antibiotic test discs were applied and incubated at $37^{\circ} \mathrm{C}$ for $24 \mathrm{~h}$.
Isolates were determined to be susceptible or resistant based on the diameter zone of inhibition using a standard interpretative chart (NCCLS 2000). Antibiotics tested include: ceftazidime, cefuroxime, gentamicin, ceftriaxone, erythromycin, cloxacillin, ofloxacin, augmentin and vancomycin.

\section{Results}

From the 100 samples collected (50 door handles; 50 toilet handles), growth on bile esculin agar (BEA) was observed in $71 \%$ of cases (Fig. 1). More growth was observed from toilet door handles $(38 / 50 ; 76 \%)$ than office door handles $(33 / 50 ; 66 \%)$. However, the characteristic black pigmentation was observed in only $35 \%$ of cases, majority of which (25/35) were from toilet door handles.

Biochemical characterisation of isolates with black pigmentation revealed a surprisingly wide array of bacterial strains (Fig. 2), considering the selective nature of the growth medium. Six different bacterial groups were represented among this subset with Enterococcus sp. making up only $14 \%$ of the isolates. All (100\%) Enterococci were isolated from toilet door handles, with none $(0 \%)$ identified from office door handles.

Antibiotic susceptibility testing revealed very high levels of resistance $(80-100 \%)$ against most of the antibiotics assayed (Fig. 3). These high levels were equally observed for isolates from toilet door handles as well as office door handles. Low levels of bacterial resistance $(0-24 \%)$ were observed only against ofloxacin and gentamicin.

An analysis of the antibiotic resistance pattern of each isolate revealed 11 unique antibiogram patterns (Table 1). Office door isolates exhibited 4 different patterns, while toilet door isolates exhibited 10 different patterns. Only one of these patterns was unique to office door handles while 7 patterns were unique to toilet door handles.

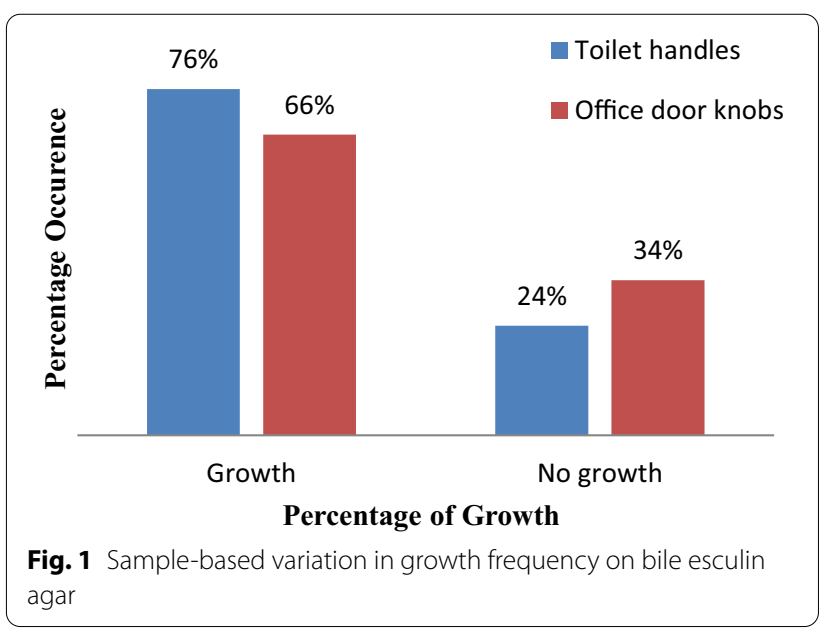




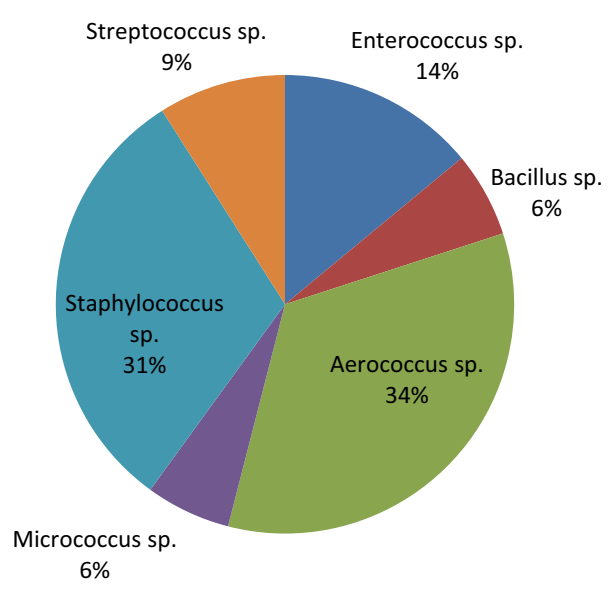

Fig. 2 Variation in bacteria groups producing black pigment on BEA associated with toilet and office door handles

\section{Multidrug resistance of isolates}

Based on the resistance pattern of each isolate, multidrug resistance (MDR, defined as resistance to 3 or more drug classes) was determined and revealed high levels of MDR in isolates from both toilet and office door handles $(88 \%$ and $80 \%$, respectively). Majority (58\%) of these MDR isolates exhibited resistance to only 3 drug classes (Fig. 4).

\section{Vancomycin resistance}

An assessment of vancomycin resistance from all isolates producing characteristic black pigmentation of BEA showed a $17 \%(6 / 35)$ rate of vancomycin resistance. A higher level of vancomycin resistance was associated with toilet door rather than office door handles (Fig. 5).
From the six vancomycin-resistant isolates a $66.7 \%$ rate of MDR was noted (4/6), with 4 different antibiogram patterns represented (Table 2).

\section{Multidrug resistance in enterococci}

Special focus on the enterococci showed that despite the numerous antibiogram patterns identified in general, only 2 patterns were represented among the enterococci (Table 3), with most isolates (4/5) showing an identical pattern of resistance. In the predominant antibiogram pattern resistance to 3 drug classes was observed, thereby indicating an $80 \%$ rate of multidrug resistance among the enterococci. None of the enterococci, however, was resistant to vancomycin.

\section{Discussion}

One major route of transmission of enterococci in hospital settings is via inanimate objects called fomites. The role of such surfaces outside of hospital settings in transmission has not been widely explored. Bacteria may live as transient contaminants on inanimate objects, especially high touch surfaces where they could serve as sources of community acquired infections. The potential role of such surfaces called fomites (Xiao 2018) in transmission has been widely explored.

The total number of samples showing growth in this study $(71 \%)$ is similar to previous reports both from within and outside Nigeria (Amala et al. 2015; Al-Harmoosh et al. 2019). Variations in number of samples showing growth could depend on a number of things such as hygiene, traffic and even temperature. This is further highlighted by the detection of more growth from toilet door handles $(38 / 50 ; 76 \%)$ than office door

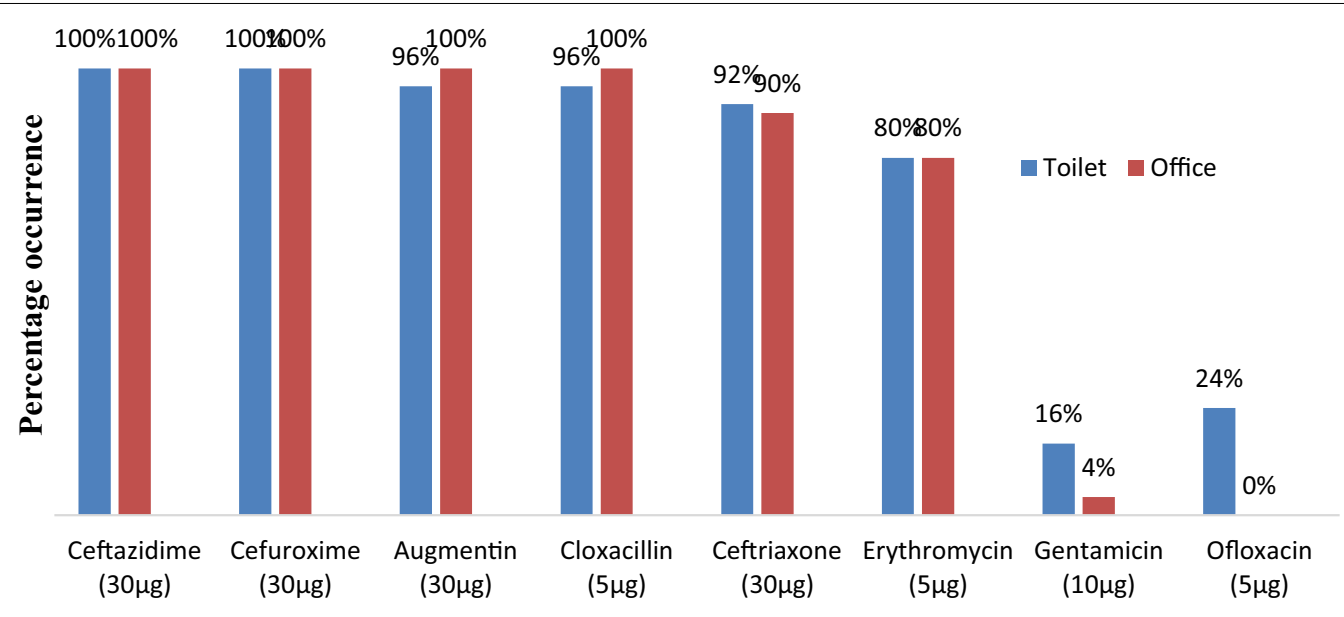

Test Antibiotics

Fig. 3 Effect of source on antibiotic resistance of bacterial isolates 
Table 1 Antibiotic resistance patterns and occurrence for toilet handles and office door knob isolates

\begin{tabular}{lll}
\hline Antibiogram & $\begin{array}{l}\text { Number } \\
\text { of toilet } \\
\text { isolates }\end{array}$ & $\begin{array}{l}\text { Number } \\
\text { of door } \\
\text { isolates }\end{array}$ \\
\hline AUG-CAZ-CRX-CXC & 1 & - \\
AUG-CAZ-CRX-CTR-CXC & 3 & 2 \\
AUG-CAZ-CRX-CXC-ERY & - & 1 \\
AUG-CAZ-CRX-CTR-CXC-ERY & 12 & 6 \\
AUG-CAZ-CRX-CTR-CXC-GEN & 1 & - \\
AUG-CAZ-CRX-CXC-ERY-OFL & 1 & - \\
CAZ-CRX-CTR-CXC-ERY-GEN & 1 & - \\
AUG-CAZ-CRX-CTR-CXC-ERY-GEN & 1 & - \\
AUG-CAZ-CRX-CTR-CXC-ERY-OFL & 2 & - \\
AUG-CAZ-CRX-CTR-ERY-GEN-OFL & 1 & - \\
AUG-CAZ-CRX-CTR-CXC-ERY-GEN-OFL & 2 & 1 \\
\hline
\end{tabular}

Augmentin (AUG), Ceftazidime (CAZ), Ceftriaxone (CTR), Cefuroxime (CRX), Cloxacillin (CXC), Erythromycin (ERY), Gentamicin (GEN), Ofloxacin (OFL)

Percentage of isolates resistant to different classes of antibiotics

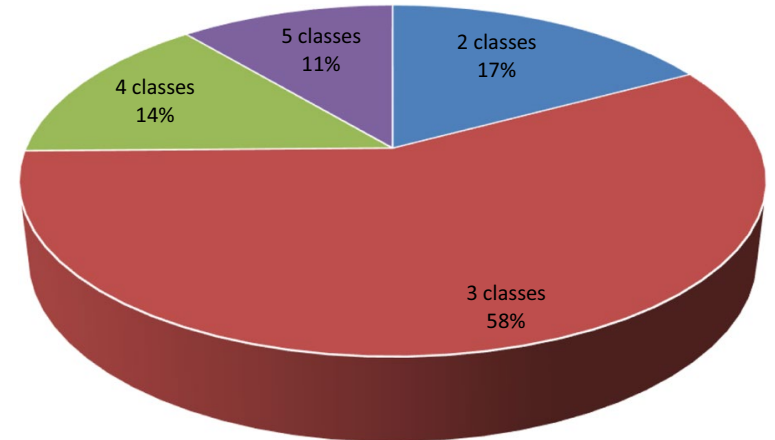

Fig. 4 Percentage of isolates resistant to different classes of antibiotics

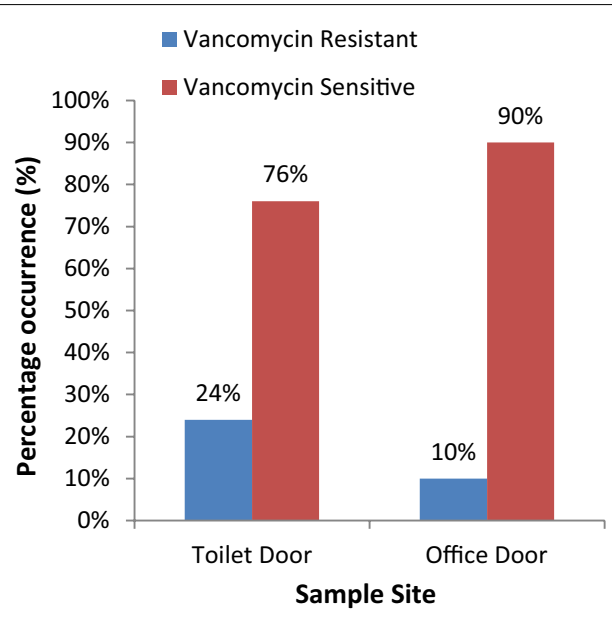

Fig. 5 Vancomycin resistance of test isolates
Table 2 Drug resistance pattern of vancomycin-resistant isolates

\begin{tabular}{lll}
\hline Antibiogram & $\begin{array}{l}\text { Number } \\
\text { of toilet } \\
\text { isolates }\end{array}$ & $\begin{array}{l}\text { Number } \\
\text { of door } \\
\text { isolates }\end{array}$ \\
\hline AUG-CAZ-CRX-CTR-CXC & - & 2 \\
AUG-CAZ-CRX-CXC-ERY & - & 1 \\
AUG-CAZ-CRX-CTR-CXC-ERY & - & 2 \\
AUG-CAZ-CRX-CTR-CXC-ERY-GEN-OFL & 1 & - \\
\hline
\end{tabular}

Augmentin (AUG), Ceftazidime (CAZ), Ceftriaxone (CTR), Cefuroxime (CRX), Cloxacillin (CXC), Erythromycin (ERY), Gentamicin (GEN), Ofloxacin (OFL)

Table 3 Drug resistance among enterococci

\begin{tabular}{ll}
\hline Antibiogram & Isolate ID \\
\hline AUG-CAZ-CRX-CTR-CXC & T27 \\
AUG-CAZ-CRX-CTR-CXC-ERY & T19, T28, T37, T50
\end{tabular}

Augmentin (AUG), Ceftazidime (CAZ), Ceftriaxone (CTR), Cefuroxime (CRX), Cloxacillin (CXC), Erythromycin (ERY), Gentamicin (GEN), Ofloxacin (OFL)

handles $(33 / 50 ; 66 \%)$. This was similar to previous reports (Odigie et al. 2017; Al-Harbi et al. 2017) and could be an indication of a higher traffic with respect to toilet door handles than office door handles. Additionally, it could represent a breakdown in basic hygiene practices following the use of the toilet facilities. Or perhaps reflect the use of wet hands on toilet door handles as opposed to office door handles, considering the higher spread of microorganisms associated with a higher moisture and humidity levels (Lopez et al. 2013; Stephens et al. 2019; Varshney et al. 2020).

This study focused on detecting enterococcus using the selective bile esculin agar, from door handles found a variety of Gram positive bacteria presented. Gram positive bacteria had actually been reported as the predominant group of organisms by a number of previous studies on bacteria associated with door handles (Al-Harbi et al. 2017; Al-Harmoosh et al. 2018, 2019). The exception to this was a 2016 study in India by Lincy and colleagues which reported a predominance of Gram negative bacteria (Lincy et al. 2016). All bacterial types identified have previously been reported as associated with door handles. Furthermore, Staphylococcus sp, Streptococcus sp and Bacillus sp have often been found as one of the 5 most prominent genera represented (Lincy et al. 2016; Odigie et al. 2017; AlHarmoosh et al. 2018; Alonge et al. 2019). For the Gram positive cocci, their presence has often been thought to be linked to their role as normal human flora, while the Bacillus sp are known hardy environmental strains due to their spore forming ability. 
This study revealed only a $14 \%$ association of Enterococcus sp with the door handles. This is similar to a 2013 study by Sabra which reported a $13.4 \%$ detection rate but differs from some previous reports with higher detection rates (Sabra 2013; Ajayi and Ekozien 2014; Al-Harbi et al. 2017) of $21 \%$ and $26 \%$ and lower detection rates (BadgerEmeka et al. 2015; Nwankwo and Afurobi 2015) of 3.5\% and $4.8 \%$. Quite a number of studies though failed to report any association of the enterococci with toilet door handles (Nworie et al. 2012; Maori et al. 2013; Bashir et al. 2016; Fakhoury and Nawas 2018). These studies in general set out to explore the total bacterial population associated with the door handles, making use of general all-purpose media and some selective media, but not selective for enterococcus. This might explain the lack of detection of the Enterococcus sp. Interestingly though in this study, the enterococci were only associated with toilet door handles. The enterococci are widely known as normal flora of the human gastrointestinal tract, where they occur without causing any harm. Furthermore, infections due to this group of organisms are associated with prior colonisation. Results of this study show that toilet door handles especially might pose a risk in the transmission of the enterococci, especially to individuals with reduced immunity making use of these shared facilities. The relationship with toilet door handles specifically could highlight that this possible route of transmission could be eliminated by proper education on the importance of hand hygiene in infection control. A similar trend of the association of enterococci with toilet door knobs has been previously reported. Al-Harbi and colleagues observed that despite the fact enterococci was isolated from different buildings in their study; in most cases it was associated primarily with toilet door handles (Al-Harbi et al. 2017).

In general, this study reports high levels of drug resistance. High levels of drug resistance are generally associated with human rather than environmental isolates (Abu et al. 2020), with purely environmental strains often associated with lower levels of drug resistance in the absence of antimicrobial selective pressure (Li et al. 2010; Chitanand et al. 2010; Hatha et al. 2015; Odonkor and Addo 2018). These results therefore indicate strongly that indeed the organisms isolated from these high touch surfaces are of human origin.

The rates of resistance described in this study were however much higher than those described in other studies. Alumbugu et al. described rates of resistance ranging from 13 to $68 \%$, with the resistance levels of above $50 \%$ observed against $60 \%$ of antibiotics (Alumbugu et al. 2019). While a study similar to this from Nigeria (Nwankwo and Afurobi 2015), also reported high rates ranging from 14.6 to $93.1 \%$, with resistance rates of above
$70 \%$ against $55.6 \%$ of antibiotics. A 2017 study by Sultana (2017), reported much lower rates ranging from 5.41 to $100 \%$ but with resistance to majority of antibiotics $(5 / 9$, $55.6 \%)$ less than $11 \%$.

Despite the limited number isolated, the resistance rates of the enterococci in this study were generally much higher than previously reported (Ferede et al. 2018; Ezeah et al. 2019; Kateete et al. 2019; Schell et al. 2020). Gentamicin and ofloxacin were the two antibiotics posing an exception, as all five enterococci were susceptible to these two. Gentamicin which belongs to the aminoglycoside family is one of the drugs of choice for the treatment of enterococcal infections (Arias et al. 2010; Ngbede et al. 2017). Some studies have reported increasing levels of gentamicin resistance (Olawale et al. 2011; Adesida et al. 2017; Ferede et al. 2018; Ezeah et al. 2019). This differs from the findings of this study which reports that despite the high level of resistance associated with the organisms, gentamicin sensitivity is still prevalent. A similar finding was recently reported (Shettima and Iregbu 2019). Another striking difference also in susceptibility pattern of the enterococcal isolates obtained from this study and others reported worldwide is the results of the ampicillin susceptibility. Ampicillin is also touted as another drug of choice for enterococcal therapy acting in synergy with the aminoglycosides. A high level of sensitivity has been noted by various other studies both within Africa and outside (Chakraborty et al. 2015; Farman et al. 2019; Kateete et al. 2019). This was not so in this present study which reported $100 \%$ resistance rates to ampicillin among the enterococci. These high level ampicillin resistance are however similar to reports from Nigeria (Olawale et al. 2011; Ezeah et al. 2019) and a 2018 Ethiopia study (Ferede et al. 2018). It could therefore point at a regional variation possibly reflective of ampicillin use in the area. Additionally, considering that E. faecalis appears to be the species specifically associated with ampicillin sensitivity, whereas E. faecium is associated with ampicillin resistance (Coombs et al. 2020), these variations could also be a reflection of variations in species within the Enterococci.

The limited number of Enterococcal isolates obtained in this study provide a major limitation for extrapolation of findings and at most could only serve as baseline data for future studies which would therefore need to employ much larger sample size to study possible roles of fomites in the spread of drug-resistant Enterococci.

\section{Conclusion}

This study exploring the potential role of door handles in the spread of drug-resistant pathogens, reports low level contamination of door handles by Enterococci. Identical antibiogram patterns linked with majority of 
the Enterococci could however point at the occurrence of a single clone perhaps indicating single source contamination. Reports of high levels of ampicillin resistance among these isolates are problematic as ampicillin-gentamicin combination is the treatment of choice for nosocomial enterococci pathogens.

\section{Abbreviations}

BEA: Bile esculin agar; MDR: Multidrug resistance; VRE: Vancomycin-resistant enterococci.

\section{Acknowledgements}

Not applicable.

\section{Authors' contributions}

$\mathrm{KO}$ conceived and designed the study. BOF and DOD carried out most of the laboratory work. KO did most of the writing. All authors read and approved the final manuscript.

\section{Funding}

The work was self-funded by the authors.

\section{Availability of data and materials}

The datasets used and/or analysed during the current study are included in this published article.

\section{Ethics approval and consent to participate}

Not applicable.

\section{Consent for publication}

Not applicable.

\section{Competing interests}

The authors declare that there are no financial or non-financial competing interests.

Received: 23 August 2020 Accepted: 4 December 2020

Published online: 10 December 2020

\section{References}

Abu GO, Otokunefor K, Dappa CD (2020) Bacteriological analysis of water quality in a recreational park pond in Rivers State, Nigeria. J Appl Sci Environ Manag 24(1):23-29

Adesida SA, Ezenta CC, Adagbada AO, Aladesokan AA, Coker AO (2017) Carriage of multidrug resistant Enterococcus faecium and Enterococcus faecalis among apparently healthy humans. Afr J Infect Dis 11(2):83-89

Ajayi A, Ekozien MI (2014) Sensitivity profile of bacterial flora isolated from bathroom. Elite Res J Biotechnol Microbiol 2(1):1-3

Al-Harbi M, Anderson A, Elmi A (2017) Evaluation of microbial contamination in frequently used Fomites in Kuwait. Biodivers Int J 1(3):80-86

Al-Harmoosh RA, Eidan AJ, Al-Hadrawy HA, Mohammed QA, Hamed AQ (2018) Potential bacterial contaminants in the handles of car doors. J Pure Appl Microbiol 12(4):2193-2198

Al-Harmoosh RA, Eidan AJ, Naji HA, Mohammad AW (2019) Potential pathogenic bacterial contaminants of doors handles and computers keyboards in the faculty environment. J Pure Appl Microbiol 13(2):975-982

Alonge OO, Auwal BM, Aboh MI (2019) Bacterial contamination of toilet door handles on Baze University campus Abuja Nigeria. Afr J Clin Exp Microbiol 20(1):35-41

Alumbugu TP, Taibat I, Haruna NI, Helma AR, David I, Grace P, Boyi NY (2019) Molecular diversity of multi-resistant and extended-spectrum beta lactamase-producing Escherichia coli from door handles in Lafia, central Nigeria. GSC Biol Pharm Sci 8(1):035-045

Amala SE, Ade AJ, Bloomfield F (2015) Bacteria associated with toilets and office lock handles. Int J Epidemiol Infect 3(1):12-15
Arias CA, Contreras GA, Murray BE (2010) Management of multidrug-resistant enterococcal infections. Clin Microbiol Infect 16(6):555-562

Badger-Emeka LI, Al-Sultan AA, Al-Dehailan HS, Al-Humini NK, Al-Najja FA, Al-Farhan HM (2015) Potential pathogenic bacterial contaminants of shared utility devices in a university setting at Al-Hofuf, Saudi Arabia. Afr J Microbiol Res 9(41):2139-2144

Bashir SF, Muhammad H, Sani NM, Kawo AH (2016) Isolation and identification of bacterial contaminants from door handles of public toilets in federal university Dutse, Jigawa State-Nigeria. IOSR J Pharm Biol Sci 11(5):53-57

Bauer AW, Kirby WMM, Strerris JC, Turk M (1966) Antibiotic susceptibility testing by a standard single disk method. Am J Clin Pathol 45:493-496

Chakraborty A, Pal NK, Sarkar S, Gupta MS (2015) Antibiotic resistance pattern of Enterococci isolates from nosocomial infections in a tertiary care hospital in Eastern India. J Nat Sci Biol Med 6(2):394-397

Cheesbrough M (2006) District laboratory practice in tropical countries Part II. Cambridge University Press, Cambridge

Chitanand MP, Kadam TA, Gyananath G, Totewad ND, Balhal DK (2010) Multiple antibiotic resistance indexing of coliforms to identify high risk contamination sites in aquatic environment. Indian J Microbiol 50(2):216-220

Coombs GW, Daley DA, Mowlaboccus S, Lee YT, Pang S, Australian Group on Antimicrobial Resistance (2020) Australian Group on Antimicrobial Resistance (AGAR) Australian Enterococcal Sepsis Outcome Programme (AESOP) annual report 2018. Commun Dis Intell. https://doi.org/10.33321 /cdi.2020.44.19

Cowan ST, Steel KJ (1985) Manual for the identification of medical bacteria, 4th edn. Cambridge University Press, London

Davis E, Hicks L, Ali I, Salzman E, Wang J, Snitkin E, Gibson K, Cassone M, Mody L, Foxman B (2020) Epidemiology of vancomycin-resistant Enterococcus faecium and Enterococcus faecalis colonization in nursing facilities. Open Forum Infect Dis 7(1):ofz553

Ezeah GAC, Ugwu MC, Ekundayo AO, Odo OF, Ike OC, Akpe RA (2019) Antibiotic susceptibility testing, plasmid detection and curing of clinically isolated Enterococcus species. J Adv Microbiol 16(3):1-20

Fakhoury S, Nawas T (2018) Contamination of the internal handles/knobs of public restroom doors with potentially pathogenic bacteria. Int J Curr Microbiol Appl Sci 7(03):3434-3440

Farman M, Yasir M, Al-Hindi RR et al (2019) Genomic analysis of multidrugresistant clinical Enterococcus faecalis isolates for antimicrobial resistance genes and virulence factors from the western region of Saudi Arabia. Antimicrob Resist Infect Control 8:55

Ferede ZT, Tullu KD, Derese SG, Yeshanew AG (2018) Prevalence and antimicrobial susceptibility pattern of Enterococcus species isolated from different clinical samples at Black Lion Specialized Teaching Hospital, Addis Ababa, Ethiopia. BMC Res Notes 11(1):1-6

Ferng YH, Clock SA, Wong-Mcloughlin J, DeLaMora PA, Perlman JM, Gray KS, Paul DA, Prasad PA, Zaoutis TE, Alba LR, Whittier S (2015) Multicenter study of hand carriage of potential pathogens by neonatal ICU healthcare personnel. J Pediatr Infect Dis Soc 4(3):276-279

García-Solache M, Rice LB (2019) The Enterococcus: a model of adaptability to its environment. Clin Microbiol Rev 32(2):e00058-e118

Gurnee EA, Ndao IM, McGhee JE, Warner BB, Tarr PI, Fritz SA, Carey-Ann BD (2014) Fecal carriage of methicillin-resistant Staphylococcus aureus and vancomycin-resistant Enterococcus in healthy children. Antimicrob Agents Chemother 58(2):1261-1262

Guzman Prieto AM, van Schaik W, Rogers MR, Coque TM, Baquero F, Corander J, Willems RJ (2016) Global emergence and dissemination of enterococci as nosocomial pathogens: attack of the clones? Front Microbiol 7:788

Hatha AM, Neethu CS, Nikhil SM, Rahiman KM, Saramma KKP (2015) Relatively high antibiotic resistance among heterotrophic bacteria from arctic ford sediments than water-evidence towards better selection pressure in the fjord sediments. Polar Sci 9(4):382-388

Kateete DP, Edolu M, Kigozi E et al (2019) Species, antibiotic susceptibility profiles and van gene frequencies among enterococci isolated from patients at Mulago National Referral Hospital in Kampala, Uganda. BMC Infect Dis 19:486

Kim HS, Kim DH, Yoon HJ, Lee WJ, Woo SH, Choi SP (2018) Factors associated with vancomycin-resistant enterococcus colonization in patients transferred to emergency departments in Korea. J Korean Med Sci 33(48):e295

Li D, Yu T, Zhang Y, Yang M, Li Z, Liu M, Qi R (2010) Antibiotic resistance characteristics of environmental bacteria from an oxytetracycline production 
wastewater treatment plant and the receiving river. Appl Environ Microbiol 76(11):3444-3451

Lincy M, Vidhya A, Ali PS, John J (2016) Determination of bacterial and fungal loads and antibiotic susceptibility testing of bacteria isolated from public toilet door handles in Vellore district, Tamilnadu, India. Int J Res Biosci 5(4):69-78

Lopez GU, Gerba CP, Tamimi AH, Kitajima M, Maxwell SL, Rose JB (2013) Transfer efficiency of bacteria and viruses from porous and nonporous fomites to fingers under different relative humidity conditions. Appl Environ Microbiol 79(18):5728-5734

Maori L, Agbor VO, Ahmed WA (2013) The prevalence of bacterial organisms on toilet door handles in Secondary Schools in Bokkos LGA, Jos, Plateau Sate, Nigeria. IOSR J Pharm Biol Sci 8(4):85-91

Michael KE, No D, Roberts MC (2017) vanA-positive multi-drug-resistant Enterococcus spp. isolated from surfaces of a US hospital laundry facility. J Hosp Infect 95(2):218-223

Murray BE (1990) The life and times of the Enterococcus. Clin Microbiol Rev 3(1):46-65

National Committee for Clinical Laboratory Standards (2000) Performance standards for antimicrobial susceptibility tests; Approved standard. 7th ed. M2-A7. National Committee for Clinical Laboratory Standards, Wayne, PA

Ngbede EO, Raji MA, Kwanashie CN, Kwaga JK, Adikwu AA, Maurice NA, Adamu AM (2017) Characterization of high level ampicillin-and aminoglycoside-resistant enterococci isolated from non-hospital sources. J Med Microbiol 66(7):1027-1032

Nwankwo EO, Afuruobi HE (2015) Isolation and identification of bacterial contaminants from door handles in a tertiary institution in Umuahia, Abia state, Nigeria. Niger J Microbiol 29:3139-3149

Nworie A, Ayeni JA, Eze UA, Azi SO (2012) Bacterial contamination of door handles/knobs in selected public conveniences in Abuja metropolis, Nigeria: a public health threat. Cont J Med Res 6(1):7-11

Odigie AB, Ekhiase FO, Orjiakor PI, Omozuwa S (2017) The role of door handles in the spread of microorganisms of public health consequences in University of Benin Teaching hospital (UBTH), Benin city, Edo state. Pharm Sci Technol 2(2):15-21

Odonkor ST, Addo KK (2018) Prevalence of multidrug-resistant Escherichia coli isolated from drinking water sources. Int J Microbiol. https://doi. org/10.1155/2018/7204013
Olawale KO, Fadiora SO, Taiwo SS (2011) Prevalence of hospital acquired enterococci infections in two primary-care hospitals in Osogbo, Southwestern Nigeria. Afr J Infect Dis 5(2):40-46

Reynolds KA, Watt PM, Boone SA, Gerba CP (2005) Occurrence of bacteria and biochemical markers on public surfaces. Int J Environ Health Res 15(3):225-234

Rosenthal M, Aiello A, Larson E, Chenoweth C, Foxman B (2014) Healthcare workers' hand microbiome may mediate carriage of hospital pathogens. Pathogens 3(1):1-3

Sabra SM (2013) Bacterial public health hazard in the public female restrooms at Taif, KSA. Middle-East J Sci Res 14(1):63-68

Schell CM, Tedim AP, Rodríguez-Baños M, Sparo MD, Lissarrague S, Basualdo JA, Coque TM (2020) Detection of $\beta$-Lactamase-producing Enterococcus faecalis and vancomycin-resistant Enterococcus faecium isolates in human invasive infections in the public hospital of Tandil, Argentina. Pathogens 9(2):142

Selleck EM, Van Tyne D, Gilmore MS (2019) Pathogenicity of Enterococci. Microbiol Spectr 7(4):10

Shettima SA, Iregbu KC (2019) Antimicrobial resistance pattern of enterococci isolated from stool samples in a tertiary hospital in Nigeria. Ann Trop Pathol 10(2):126-131

Stephens B, Azimi P, Thoemmes MS, Heidarinejad M, Allen JG, Gilbert JA (2019) Microbial exchange via fomites and implications for human health. Curr Pollut Rep 5(4):198-213

Sultana I (2017) Prevalence, antibiotic susceptibility and plasmid profile of bacteria from door knobs of female restrooms in BRAC University, Dhaka. Doctoral dissertation. BRAC University

Varshney S, Pandey P, Gupta D, Sharma S (2020) Role of fabric properties, moisture and friction in transfer of bacteria from fabric to fabric. Text Res J 90(3-4):478-485

Xiao S (2018) The role of fomites in disease spread and the transmission characteristics. HKU Theses Online (HKUTO)

\section{Publisher's Note}

Springer Nature remains neutral with regard to jurisdictional claims in published maps and institutional affiliations.

\section{Submit your manuscript to a SpringerOpen ${ }^{\circ}$ journal and benefit from:}

- Convenient online submission

- Rigorous peer review

- Open access: articles freely available online

- High visibility within the field

- Retaining the copyright to your article

Submit your next manuscript at $\boldsymbol{\nabla}$ springeropen.com 